\title{
Rancang Bangun Aplikasi Edutainment untuk Anak SD dengan Teknik Gamifikasi Berbasis Octalysis dan Machinations Framework
}

\author{
Ardha Putra Santika, Darlis Herumurti, Imam Kuswardayan \\ Jurusan Teknik Informatika, Fakultas Teknologi Informasi, Institut Teknologi Sepuluh Nopember (ITS) \\ Jl. Arief Rahman Hakim, Surabaya 60111 Indonesia \\ e-mail:darlis.herumurti@gmail.com,imam@its.ac.id
}

\begin{abstract}
Abstrak-Teknologi berbasis edukasi terasa kurang begitu nampak aplikasinya di ranah pendidikan. Banyak faktor penarik, di antaranya lemahnya sisi User experience. Gamifikasi menawarkan perancangan aplikasi yang menyematkan elemen game sehingga lebih memiliki daya tarik terhadap konten aplikasi karena konsep game yang telah dikenal menyenangkan dan mudah dipahami. Konsep gamifikasi dirancang dengan Octalysis Framework yang menganalisis dari delapan sisi psikologi game. Perancangan gamifikasi kemudian divisualisasikan secara interaktif melalui Machinations Framework. Selanjutnya, diimplementasikan pada platform mobile menjadi aplikasi Edutainment. Didapatkan dari pengujian usabilitas sepuluh penguji bahwa gamifikasi yang diujikan memiliki dampak membuat aplikasi lebih menarik, edukatif, tidak membosankan, dan bisa meningkatkan ketertarikan anak dalam belajar.
\end{abstract}

Kata Kunci-Edutainment, Gamifikasi, Machinations, Octalysis

\section{PENDAHULUAN}

ESATNYA perkembangan aplikasi sekarang dapat dilihat Ddari banyaknya aplikasi yang diunduh, semisal pada AppStore [1]. Hal ini memicu ketatnya kompetisi para pengembang aplikasi untuk mengembangkan aplikasi, salah satunya yaitu Edutainment.

Aplikasi Edutainment bertujuan sebagai aplikasi pembelajaran dengan konsep yang menyenangkan. Namun demikian, aplikasi Edutainment cenderung tidak digandrungi karena dinilai membosankan dan tidak menarik, walaupun dasarnya merupakan aplikasi yang bermanfaat.

Dari hasil pengamatan pada beberapa kasus didapat bahwa salah satu faktor gugurnya sebuah aplikasi dari persaingan adalah karena rendahnya user engagement [2], baik dari konsep maupun dari UX (User experience). Dan benar dapat dilihat bahwa aplikasi Edutainment sudah hampir tidak pernah dijumpai, minimal tidak populer, di kalangan pengguna dan juga marketplace.

Maka dari itu, muncul teknik gamifikasi yang mengadopsi konsep game sebagai solusi untuk permasalahan aplikasi yang rendah kualitas user engagement-nya. Teknik gamifikasi didefinisikan dengan menyematkan elemen-elemen game pada konteks aplikasi non-game [3]. Teknik gamifikasi merupakan tren UX yang sedang banyak dibahas oleh para peneliti di berbagai jurnal ilmiah [4].

Penggunaan teknik gamifikasi dalam desain UX penting untuk meningkatkan user engagement dan melanggengkan interaksi pengguna dan aplikasi lebih lama sehingga muncul loyalitas dari pengguna. Hal tersebut merupakan keuntungan dari sisi nilai bisnis. Sedangkan dari sisi pengguna sendiri penting untuk membangun motivasi secara internal dalam menggunakan aplikasi tersebut [3].

Dengan keuntungan-keuntungan yang dipaparkan, teknik gamifikasi diharapkan mampu menyelesaikan permasalahan user engagement pada aplikasi yang sebenarnya memiliki potensi nilai yang besar, seperti aplikasi Edutainment.

Dalam pembahasan ke depan, terdapat beberapa bab. Bab II membahas tentang metodologi penelitian dari jurnal ini. Metodologi penelitian berkaitan dengan analisis desain dan perancangan aplikasi Edutainment. Bab III membahas tentang hasil dan pembahasan dari bab II. Bab ini memuat tentang hasil pengujian dari perancangan aplikasi yang telah dilakukan. Bab IV membahas tentang kesimpulan dan saran pengembangan setelah didapatkan hasil pengujian dari aplikasi.

\section{METODOLOGI PENELITIAN}

\section{A. Spesifikasi Kebutuhan}

Untuk mengembangkan aplikasi edukasi yang interaktif dan efektif untuk pembelajaran, dibutuhkan spesifikasi kebutuhan fungsional yang direpresentasikan oleh diagram kasus penggunaan. Sebelumnya, aplikasi terlebih dahulu dideskripsikan secara umum agar diketahui garis besar dan tujuan dari aplikasi yang dirancang.

\section{B. Perancangan Gamifikasi}

Perancangan gamifikasi menggunakan Octalysis Framework [5]. Elemen-elemen gamifikasi didefinisikan melalui analisis diagram Octalysis. Kemudian, elemen-elemen disematkan pada fitur-fitur aplikasi yang berdasarkan spesifikasi kebutuhan aplikasi.

\section{Perancangan Gameplay}

Perancangan gameplay/alur dari aplikasi menggunakan Machinations Framework [6] yang mendefinisikan alur distribusi komponen aplikasi serta mengimplementasikan konsep gamifikasi yang telah dirancang. Tidak semua konsep gamifikasi dimasukkan pada perancangan alur aplikasi karena tidak seluruhnya merupakan komponen yang dapat terimplementasikan atau eksplisit. 


\section{Perancangan User Interface (UI)}

Perancangan UI merupakan implementasi desain akhir dari perancangan gamifikasi dan gameplay. Perancangan UI hanya untuk menunjukkan konsep gamifikasi yang telah dirancang.

\section{E. Pengujian Fungsionalitas}

Pengujian fungsionalitas dilakukan untuk menguji apakah fungsionalitas yang diidentifikasi pada tahap kebutuhan benarbenar diimplementasikan dan bekerja semestinya. Selain itu, langkah ini ditujukan untuk mengetahui kesesuaian keluaran dari setiap tahapan atau langkah penggunaan fitur terhadap skenario yang dipersiapkan. Pengujian dilakukan dengan metode black-box [7].

\section{F. Pengujian Usabilitas}

Pengujian pada aplikasi yang dibangun tidak hanya dilakukan pada fungsionalitas yang dimiliki, tetapi juga pada pengguna untuk percobaan secara langsung. Pengujian ini berfungsi sebagai pengujian subjektif yang bertujuan untuk mengetahui tingkat keberhasilan aplikasi yang dibangun dari sisi pengguna. Hal ini dapat dicapai dengan meminta penilaian dan tanggapan dari pengguna terhadap sejumlah aspek aplikasi yang ada.

\section{UJI COBA DAN ANALISIS}

\section{A. Analisis Spesifikasi Kebutuhan}

Analisis spesifikasi kebutuhan didapatkan dari penjabaran deskripsi aplikasi. Pendeskripsian aplikasi kemudian mendefinisikan kebutuhan-kebutuhan fungsional dari aplikasi. Kebutuhan fungsional aplikasi ini direpresentasikan dalam bentuk diagram kasus penggunaan.

\section{1) Deskripsi Aplikasi}

Aplikasi yang dikembangkan ialah sebuah aplikasi edukasi yang berbasis aktivitas pembelajaran di kelas, dinamakan EduApp. EduApp mengadaptasi konsep gamifikasi, di mana mengedepankan proses aktivitas dan interaksi antarkarakteristik pengguna di kelas secara interaktif.

Di samping itu, EduApp dirancang menjadi sebuah aplikasi yang membangkitkan motivasi belajar siswa lewat interaksi mereka ke dalam aplikasi yang berupa sebuah 'gameplay' layaknya game. Siswa diajak untuk bermain secara pasif. Artinya, aktivitas bermain ini sebenarnya merupakan bagian dari pembelajaran dalam kelas, hanya saja dibentuk dalam sebuah konteks permainan.

Aplikasi EduApp dirancang untuk dua domain pengguna, yakni siswa dan guru. Masing-masing pengguna memiliki karakteristik yang berbeda seperti yang tertera pada Tabel 1 . EduApp merancang sebuah aplikasi yang interaktif, khususnya di dalam sebuah kelas, sehingga interaksi antara siswa dan guru bisa lebih baik dan menyenangkan, serta menjadi sarana pembelajaran secara kognitif dan afektif yang efektif.

\section{2) Analisis Kebutuhan Fungsional}

Kebutuhan fungsional didefinisikan berdasarkan deskripsi aplikasi yang didefinisikan di bagian sebelumnya dan karakteristik pengguna. Perancangan dari hasil analisis kebutuhan fungsional EduApp direpresentasikan dalam bentuk diagram kasus penggunaan. Diagram kasus penggunaan ditampilkan pada Gambar 1. Masing-masing kasus penggunaan memiliki penjelasan keterangan. Keterangannya tercantum pada Tabel 2.

Tabel 1.

Karakteristik pengguna EduApp.

\begin{tabular}{|c|c|c|c|}
\hline $\begin{array}{c}\text { Nama } \\
\text { Pengguna }\end{array}$ & Karakteristik & $\begin{array}{l}\text { Hak Akses } \\
\text { Aplikasi }\end{array}$ & $\begin{array}{c}\text { Kemampuan } \\
\text { yang Harus } \\
\text { Dimiliki } \\
\end{array}$ \\
\hline Siswa & $\begin{array}{c}\text { Melakukan } \\
\text { pembelajaran }\end{array}$ & Pengguna & Tidak ada \\
\hline Guru & $\begin{array}{l}\text { Melakukan pengawasan, } \\
\text { melihat progres siswa, } \\
\text { menilai siswa }\end{array}$ & Pengguna & $\begin{array}{c}\text { Memahami } \\
\text { aplikasi Android }\end{array}$ \\
\hline
\end{tabular}

Tabel 2.

Kasus penggunaan EduApp.

\begin{tabular}{|c|c|c|}
\hline $\begin{array}{l}\text { Kode Kasus } \\
\text { Penggunaan }\end{array}$ & $\begin{array}{l}\text { Nama Kasus } \\
\text { Penggunaan }\end{array}$ & Keterangan \\
\hline UC-001 & Memilih Peran & $\begin{array}{c}\text { Siswa memilih sebuah peran yang } \\
\text { diinginkan untuk acuan yang } \\
\text { digunakan pada aplikasi }\end{array}$ \\
\hline UC-002 & Melakukan Evaluasi & $\begin{array}{l}\text { Siswa melakukan evaluasi untuk } \\
\text { mendapatkan nilai }\end{array}$ \\
\hline UC-003 & $\begin{array}{l}\text { Melihat Progres } \\
\text { Pencapaian }\end{array}$ & $\begin{array}{c}\text { Siswa melihat perkembangan } \\
\text { terhadap yang dihasilkan selama } \\
\text { penggunaan aplikasi }\end{array}$ \\
\hline UC-004 & $\begin{array}{l}\text { Mendapatkan } \\
\text { Reward }\end{array}$ & $\begin{array}{l}\text { Siswa memilih dan mendapatkan } \\
\text { reward sesuai ketentuan }\end{array}$ \\
\hline UC-005 & $\begin{array}{l}\text { Melihat Pencapaian } \\
\text { Siswa }\end{array}$ & $\begin{array}{c}\text { Guru melihat pencapaian seluruh } \\
\text { siswa di kelas }\end{array}$ \\
\hline UC-006 & Menilai Siswa & $\begin{array}{l}\text { Guru menilai siswa dari beberapa } \\
\text { faktor yang mempengaruhi nilai } \\
\text { siswa di aplikasi }\end{array}$ \\
\hline
\end{tabular}

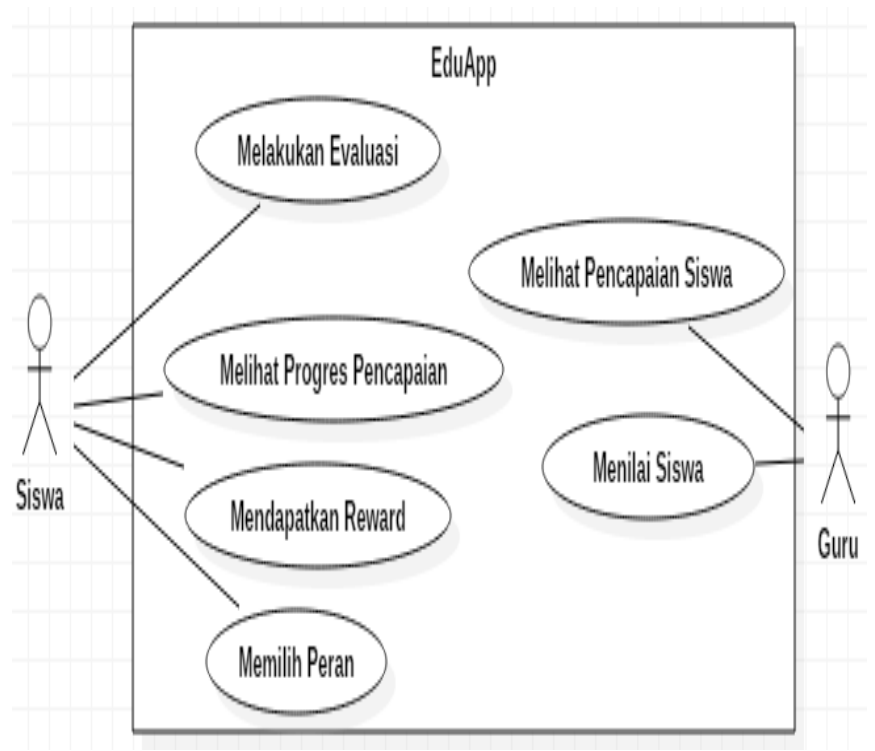

Gambar 1. Diagram kasus penggunaan EduApp. 


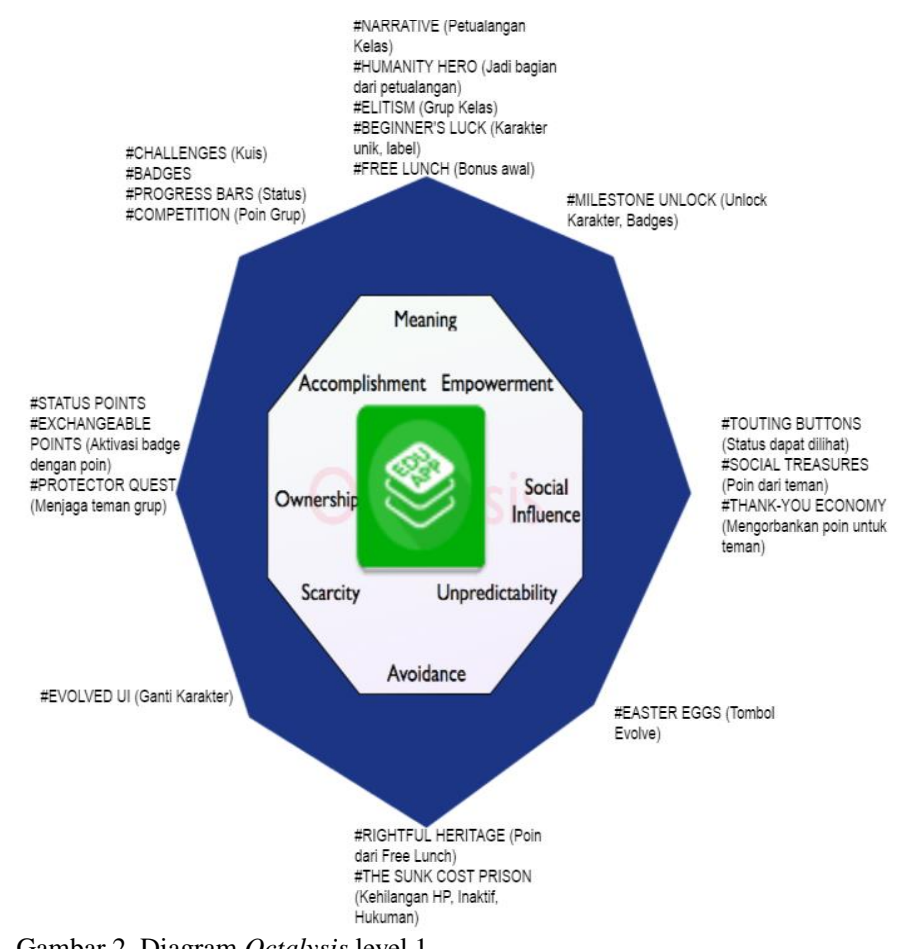

Gambar 2. Diagram Octalysis level 1.

\section{B. Analisis Gamifikasi dengan Octalyisis Framework}

Perancangan konsep gamifikasi pada aplikasi EduApp menggunakan Octalysis Framework. Elemen gamifikasi yang dirancang pada diagram Octalysis di Gambar 2 merupakan pemetaan berdasarkan kebutuhan fungsional yang telah didefinisikan pada bagian sebelumnya.

\section{1) Core Drive 1: Epic Meaning and Calling}

Perancangan Core Drive 1 memuat beberapa game mechanics yang didesain untuk aplikasi EduApp, yakni:

\section{1) Narrative}

Narrative yang digunakan pada EduApp yakni tentang pengenalan sesuatu yang baru di dalam kelas, yakni sebuah petualangan. Para siswa akan belajar layaknya berpetualang dalam melakukan aktivitas-aktivitas di dalam kelas. Narrative diimplementasikan berupa pendahuluan aplikasi sebelum masuk ke menu utama.

\section{2) Humanity Hero}

Penggunaan dari Humanity Hero dalam EduApp adalah siswa dihadirkan rasa petualang dalam kelas. Mereka menjadi andil dalam bagian petualangan di kelasnya. Humanity Hero diimplementasikan berupa pendahuluan aplikasi sebelum masuk ke menu utama.

\section{3) Elitism}

Elitism muncul di dalam EduApp melalui adanya grup di dalam aplikasi. Siswa akan memilih sebuah grup dan bergabung dengan siswa lain. Kemudian, mereka akan bersaing dengan grup yang lain.

\section{4) Beginner's Luck}

Beginner's Luck ditunjukkan pada EduApp dalam pemilihan peran. Siswa memilih peran yang akan membuat dia merasa pantas dan terpilih dalam menggunakan peran tersebut.

\section{5) Free Lunch}

Free Lunch digunakan pada EduApp dalam pemberian poin awal sebelum masuk ke aplikasi utama.

\section{2) Core Drive 2: Development and Accomplishment}

Perancangan Core Drive 2 pada EduApp menggunakan beberapa game mechanics yang terkait, yakni:

1) Challenges

Challenges digunakan dalam EduApp dalam bentuk kuis. Siswa akan melakukan evaluasi berupa kuis yang menjadi tantangan utama dalam aplikasi.

\section{2) Badges}

Badges ditampilkan dalam EduApp sebagai pencapaian yang diraih oleh siswa. Dan badges tersebut dapat digunakan sesuai dengan deskripsinya sesuai dengan ketentuan yang ada.

\section{3) Progress Bars}

Progress Bars digunakan dalam EduApp pada progress bars atribut status siswa. Siswa memiliki beberapa status yang akan ditampilkan dalam bentuk progress bars dan bisa dilihat perkembangannya kapan pun.

4) Competition

Competition hadir dalam EduApp dalam bentuk poin grup. Siswa akan berlomba-lomba mengumpulkan poin grup terbanyak untuk mengalahkan grup yang lain.

\section{3) Core Drive 3: Empowerment of Creativity and Feedback}

Perancangan Core Drive 3 dalam EduApp mengimplementasikan game mechanics, yaitu:

\section{1) Milestone Unlock}

Pada EduApp, Milestone Unlock digunakan pada unlock badges dan karakter. Siswa akan mendapatkan karakter dan badges baru bila terpenuhi syarat level.

\section{4) Core Drive 4: Ownership and Possession}

Perancangan Core Drive 4 pada EduApp menggunakan beberapa game mechanics yang terkait, yakni:

\section{1) Status Points}

Status Points dalam EduApp digunakan dalam atribut nilai siswa. Siswa memiliki atribut-atribut nilai, di antaranya HP (Health Points) dan XP (eXperience Points). Kemudian, siswa dalam ranah grup memiliki atribut nilai berupa poin grup yang dimiliki masing-masing grup.

2) Exchangeable Points

ExchangeablePoints dalam EduApp digunakan sebagai atribut AP (Armor Points). AP digunakan sebagai aktivasi badges yang tersedia.

\section{3) Protector Quest}

Protector Quest dalam EduApp diwujudkan dalam bentuk teman grup. Dalam badges, siswa bisa memberikan teman grupnya berupa tambahan poin $\mathrm{HP}$, AP, dan XP agar teman grupnya tidak kekurangan.

\section{5) Core Drive 5: Social Influence and Relatedness}

Perancangan Core Drive 5 pada EduApp menggunakan beberapa game mechanics yang terkait, yakni:

\section{1) Touting Buttons}

Touting Buttons dalam EduApp digunakan pada daftar siswa di mana siswa yang lain bisa melihat atribut siswa.

\section{2) Social Treasures}

Social Treasures dalam EduApp digunakan pada fungsi Badges yang mana pengguna dapat menerima pemberian poin oleh siswa lain.

3) Thank-You Economy 
Thank-You Economy dalam EduApp digunakan pada aktivasi badges di mana siswa dapat memberikan poin kepada siswa lain dengan mengorbankan poinnya sendiri.

\section{6) Core Drive 6: Scarcity and Impatience}

Perancangan Core Drive 6 pada EduApp menggunakan beberapa game mechanics yang terkait, yakni:

1) Evolved UI

Evolved UI pada EduApp dimunculkan pada evolusi karakter saat level tercapai. Karakter akan berubah wujud bila level yang diharuskan telah tercapai.

\section{7) Core Drive 7: Curiousity and Unpredictability}

Perancangan Core Drive 7 dalam EduApp menggunakan game mechanics, yakni:

1) Easter Eggs

Easter Eggs pada EduApp digunakan pada tombol evolusi. Yakni, siswa bisa saja memencet-mencet tombol tersebut, lalu karena level yang naik dengan tak diduga-duga (karena faktor skor XP dari guru) sehingga mengevolusikan karakter menjadi karakter yang baru.

\section{8) Core Drive 8: Loss and Avoidance}

Perancangan Core Drive 8 pada EduApp menggunakan beberapa game mechanics yang terkait, yakni:

1) Rightful Heritage

Rightful Heritage digunakan dalam EduApp pada Free Lunch di awal untuk menimbulkan rasa kepemilikan siswa terhadap Status Points. Dan agar siswa tidak ingin kehilangan setelah diberikan.

2) The Sunk Cost Prison

The Sunk Cost Prison digunakan dalam EduApp pada Status Points HP. Siswa akan menjadi inaktif selama beberapa waktu ketika dia kehilangan seluruh HP-nya. Juga, ketika kehilangan seluruh HP, siswa akan mendapatkan hukuman.

\section{Perancangan Gameplay menggunakan Machinations \\ Framework}

Perancangan gameplay menjelaskan alur aplikasi yang dibangun pada aplikasi, kemudian divisualisasikan secara interaktif melalui Machinations Framework, dan berikutnya penjelasan elemen dan alur aplikasi pada diagram Machinations Framework.

\section{1) Deskripsi Gameplay}

Aplikasi EduApp memiliki dua karakteristik pengguna, yaitu siswa dan guru. Siswa diilustrasikan sebagai pemain yang aktif, sehingga subjek perancangan alur pada aplikasi ini ialah siswa.

Implementasi awal EduApp yaitu pada fase Discovery (penamaan fase berdasarkan teori Octalysis Framework level 2 [8]), di mana siswa baru memasuki sistem aplikasi dan mengenal. Fase ini mengimplementasikan sejumlah game mechanics; yang dimodelkan pada alur aplikasi adalah Humanity Hero, Beginner's Luck, Elitism, Narrative, dan Free Lunch.
Siswa mulai memilih salah satu karakter aplikasi. Masingmasing karakter memiliki HP dan AP awal yang berbeda-beda. Kemudian, siswa memilih grupnya. Di sini siswa akan menemukan pemain lain yang satu grup dengannya. Setelah itu, siswa memasuki sebuah 'Epic Intro' yang berhubungan dengan Humanity Hero dan Narrative. Pada akhir fase Discovery, dimunculkan Free Lunch berupa bonus XP.

Kemudian alur dilanjutkan pada fase Onboarding. Fase ini merupakan fase di mana siswa mulai mengenali alur utama dan aturan aplikasi. Implementasi di dalamnya adalah Progress Bars, Badges, Status Points, Touting Buttons, dan Evolved UI. Siswa memasuki halaman utama berupa UI yang menampilkan karakter yang telah dipilih. Kemudian, siswa bisa melihat Status Points, yaitu HP, AP, dan XP yang menjadi atribut nilai pegangan selama menggunakan aplikasi. Siswa juga bisa melihat macam-macam Badges yang bisa didapat.

Fase berikutnya adalah fase Scaffolding. Fase ini merupakan fase siswa mulai menggunakan aplikasi setelah mengenal alur dan misi utama aplikasi. Fase Scaffolding diimplementasikan oleh game mechanics Challenges, Competitions, Exchangeable Points, Protector Quest, Elitism, Social Treasures, dan Thank-You Economy. Siswa melakukan aktivitas-aktivitas untuk mencapai goal dari aplikasi. Challenges yaitu di mana siswa melakukan evaluasi berupa mengerjakan kuis. Hasil dari kuis adalah atribut power yang diakumulasikan dengan sesama anggota grup untuk menjadi poin grup. Dari poin grup ini, muncul Competitions, yaitu Elitism antargrup.

Siswa selanjutnya memiliki aktivitas untuk mengaktifkan Badges, sesuai level dan ketentuan yang ada. Di antara Badges memungkinkan kemampuan siswa untuk memberikan poin status kepada teman grupnya dengan mengorbankan nilai APnya. Di sini mengimplementasikan Protector Quest, Thank-You Economy, dan Social Treasures. Dan juga terdapat Milestone Unlock di mana ini akan meng-unlock badges dan karakter, serta Easter Eggs.

Fase yang terakhir adalah fase Endgame. Fase ini bertujuan mempertahankan pemain untuk tetap menggunakan aplikasi selepas goal dari aplikasi telah tercapai. Di sini EduApp mengimplementasikan game mechanics The Sunk Cost Prison. Siswa akan mengalami inaktif akun bila dia mencapai nilai 0 pada status HP.

\section{2) Diagram Machinations Framework}

Ilustrasi alur aplikasi EduApp divisualisasikan dengan Machinations Framework. Machinations Framework memungkinkan pembuatan diagram alur aplikasi yang lebih fleksibel dan mudah dipahami karena berbasis workflow gameplay dari sebuah permainan.

Keterkaitan gamifikasi dengan permainan menjadikan Machinations Framework tepat untuk diimplementasikan pada Gambar 3. 


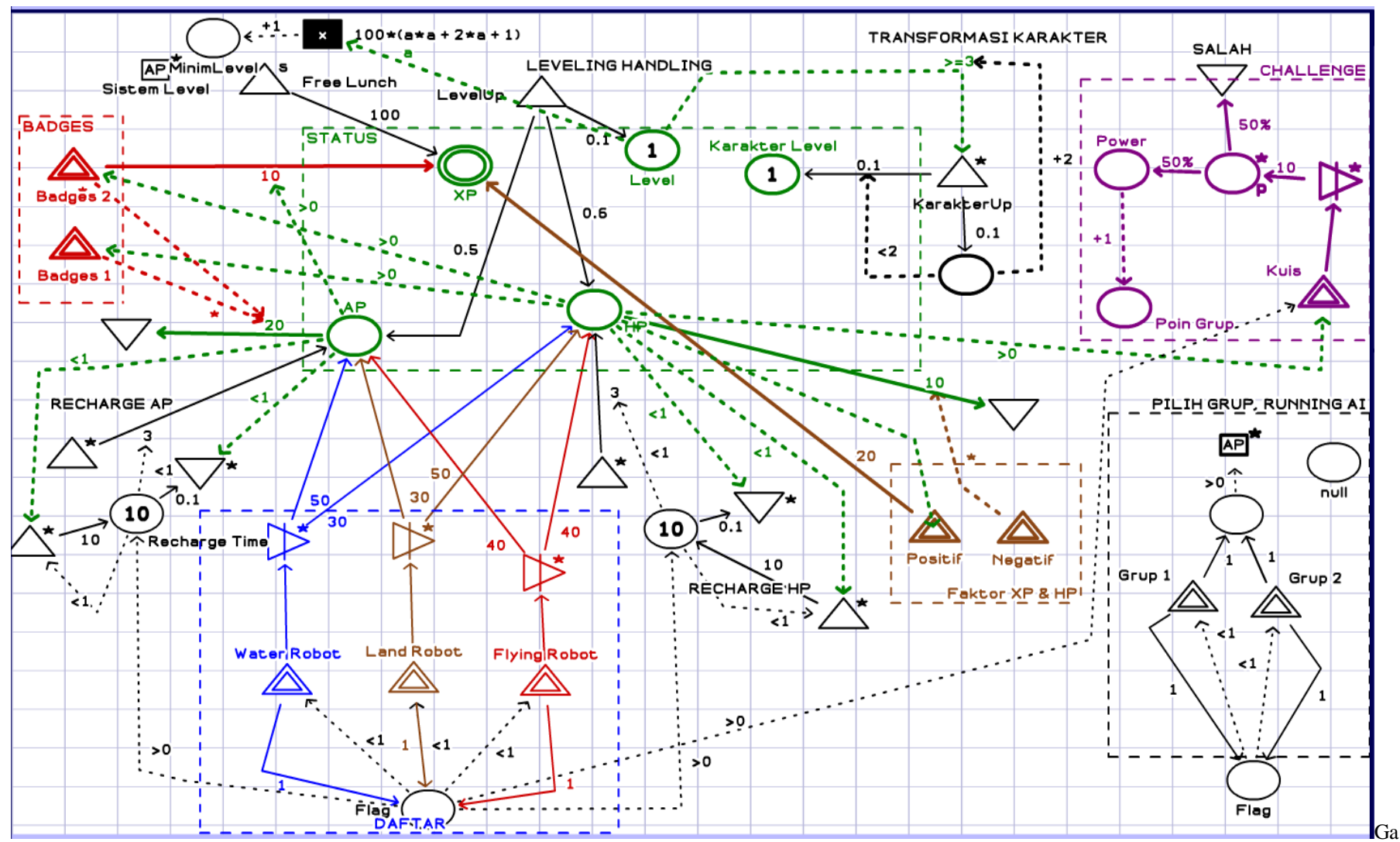

Gambar 3. Diagram Machinations Framework.

\section{Implementasi UI}

Implementasi UI dan sistemnya menggunakan Android Studio berbasis XML dan Java. Terdapat beberapa contoh UI untuk menunjukkan hasil dari perancangan konsep gamifikasi yang ditanamkan pada aplikasi EduApp. Ditunjukkan pada Gambar 4, yaitu implementasi dari elemen gamifikasi Milestone Unlock dan Evolved UI.

\section{E. Pengujian Fungsionalitas}

Tabel 3 menunjukkan hasil dari pengujian fungsionalitas berdasarkan diagram kasus penggunaan yang telah dispesifikasikan sebelumnya.

\section{F. Pengujian Usabilitas}

Skala nilai uji dalam pengujian usabilitas terhitung dari satu hingga empat, mulai dari skala terendah ke skala tertinggi. Penilaian pengujian usabilitas berupa kemudahan penggunaan aplikasi dan ketertarikan terhadap aplikasi serta kebermanfaatannya.

Pengujian dilakukan terhadap sepuluh orang penguji yang memiliki latar belakang profesi yang berbeda-beda. Hasil penilaian usabilitas ditunjukkan oleh Tabel 4. Sedangkan pengujian usabilitas ke-2 berupa penilaian elemen gamifikasi dan dampaknya pada aplikasi, yakni tercantum pada Tabel 5 .

\section{KESIMPULAN DAN SARAN PENGEMBANGAN}

Setelah mendapatkan hasil pengujian dari perancangan aplikasi EduApp, dapat ditarik kesimpulan bahwa mulai dari tahap analisis, desain, implementasi, hingga pengujian sebagai berikut:

1) Berdasarkan pengujian fungsionalitas, aplikasi berhasil mengimplementasikan sejumlah kebutuhan fungsional dan desain perancangan aplikasi yang telah dibangun sebelumnya dengan baik.

2) Berdasarkan pengujian usabilitas, aplikasi memiliki kebergunaan yang baik dilihat dari rata-rata subjektivitas pengguna yang mencapai skor $80 \%$.

3) Berdasarkan pengujian usabilitas, aplikasi dinilai memberikan dampak yang mampu memberi user engagement yang lebih menarik (7 dari 10 penguji), lebih edukatif ( 1 dari 10 penguji), tidak membosankan ( 1 dari 10 penguji), membuat ketertarikan anak dalam belajar bertambah ( 2 dari 10 penguji), namun ada kecenderungan membuat anak bermain tab yang lebih tinggi (1 dari 10 penguji).

Adapun masih terdapat beberapa hal yang perlu dikembangan agar konsep gamifikasi yang dibangun dapat diimplementasikan ke dalam lingkungan pengujian yang riil. Berikut saran pengembangan yang diharapkan dapat dikembangan di penelitian berikutnya:

1) Desain tampilan perlu dibuat lebih nyaman dan ramah bagi pengguna.

2) Fitur-fitur terkait pembelajaran perlu dikembangkan, semisal animasi pembelajaran.

Aplikasi diimplementasikan dalam lingkungan pengujian yang riil, yaitu pengujian di dalam kelas, dengan lama waktu minimal satu masa penilaian guru. 


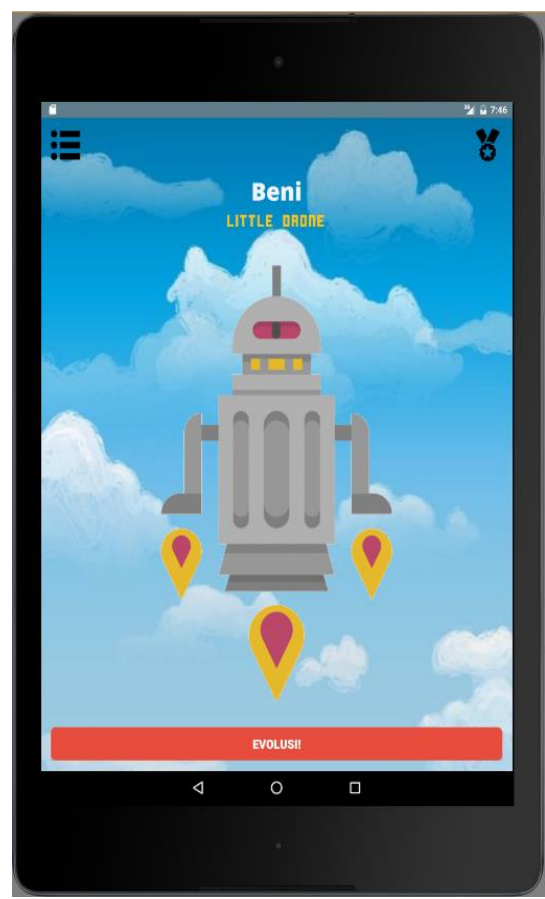

Gambar 4. UI home siswa mengimplementasikan elemen gamifikasi Milestone Unlock dan Evolved UI.

Tabel 3.

Hasil pengujian fungsionalitas per kasus penggunaan.

\begin{tabular}{|c|c|c|}
\hline $\begin{array}{l}\text { Kebutuhan } \\
\text { Fungsional }\end{array}$ & Output yang Diharapkan & Hasil Pengujiar \\
\hline $\begin{array}{l}\text { UC-001: Memilih } \\
\text { Peran }\end{array}$ & $\begin{array}{c}\text { Pilihan karakter } \\
\text { tersimpan sebagai atribut } \\
\text { pengguna dan dapat } \\
\text { ditampilkan setelah } \\
\text { pendaftaran dan masuk } \\
\text { akun }\end{array}$ & Berhasil \\
\hline $\begin{array}{c}\text { UC-002: Melakukan } \\
\text { Evaluasi }\end{array}$ & $\begin{array}{c}\text { Pengguna mendapatkan } \\
\text { hasil dari pengerjaan kuis } \\
\text { dan tersimpan dalam } \\
\text { database }\end{array}$ & Berhasil \\
\hline $\begin{array}{l}\text { UC-003: Melihat } \\
\text { Progres Pencapaian }\end{array}$ & $\begin{array}{l}\text { Halaman status points } \\
\text { menampilkan progres } \\
\text { status terbaru dan histori } \\
\text { aktivitas yang dia lakukan }\end{array}$ & Berhasil \\
\hline $\begin{array}{l}\text { UC-004: } \\
\text { Mendapatkan } \\
\text { Reward }\end{array}$ & $\begin{array}{c}\text { Pengguna mendapatkan } \\
\text { kemampuan badges } \\
\text { sesuai badges yang } \\
\text { dipilih }\end{array}$ & Berhasil \\
\hline $\begin{array}{l}\text { UC-005: Melihat } \\
\text { Pencapaian Siswa }\end{array}$ & $\begin{array}{c}\text { Pengguna guru } \\
\text { mendapatkan tampilan } \\
\text { pencapaian siswa yang } \\
\text { dipilih }\end{array}$ & Berhasil \\
\hline $\begin{array}{l}\text { UC-006: Menilai } \\
\text { Siswa }\end{array}$ & $\begin{array}{l}\text { Sistem memperbarui nilai } \\
\text { status points siswa setelah } \\
\text { pengguna guru } \\
\text { menyetujui }\end{array}$ & Berhasil \\
\hline
\end{tabular}

Tabel 4.

Hasil pengujian usabilitas 1 .

\begin{tabular}{cc}
\hline \hline Penilaian & Rata-Rata \\
\hline Kemudahan Dipahami & 3,2 \\
Kemudahan Digunakan & 3,3 \\
Kesesuaian Konteks & 3,0 \\
Kelengkapan Fitur & 2,9 \\
Kelebihan Potensi Aplikasi & 2,9 \\
Keindahan Tampilan & 3,5
\end{tabular}

\begin{tabular}{|c|c|c|}
\hline \multicolumn{2}{|c|}{$\begin{array}{c}\text { Ketertarikan Penggunaan } \\
\text { Nilai Akhir } \\
\end{array}$} & $\begin{array}{c}3,3 \\
3,2 \\
3,2=80 \% \\
\end{array}$ \\
\hline \multicolumn{3}{|c|}{$\begin{array}{c}\text { Tabel } 5 \text {. } \\
\text { Hasil pengujian } \text { usabilitas } 2 .\end{array}$} \\
\hline $\begin{array}{l}\text { Nomor } \\
\text { Penguji }\end{array}$ & $\begin{array}{c}\text { Elemen Gamifikasi yang } \\
\text { Menarik } \\
\end{array}$ & Dampak Gamifikasi pada Aplikasi \\
\hline 1 & List siswa, grup kelas & $\begin{array}{l}\text { Lebih menarik dan tidak } \\
\text { membosankan }\end{array}$ \\
\hline 2 & - & - \\
\hline 3 & $\begin{array}{l}\text { Kuis, tombol evolusi, } \\
\text { karakter }\end{array}$ & Mirip pada aplikasi game \\
\hline 4 & Karakter, histori, kuis & $\begin{array}{l}\text { Monitoring aktivitas lebih mudah, } \\
\text { kecenderungan siswa bermain tab } \\
\text { lebih tinggi }\end{array}$ \\
\hline 5 & Sistem poin mirip game & $\begin{array}{c}\text { Pembelajaran telah dikemas dalam } \\
\text { bentuk yang menarik }\end{array}$ \\
\hline 6 & $\begin{array}{l}\text { Evolusi, karakter } \\
\text { berwarna-warni }\end{array}$ & Lebih menarik \\
\hline 7 & Gambar & Menarik \\
\hline 8 & $\begin{array}{l}\text { Sistem penilaian dari } \\
\text { guru dan hukuman }\end{array}$ & $\begin{array}{l}\text { Aplikasi akan semakin menarik } \\
\text { dan edukatif }\end{array}$ \\
\hline 9 & Konten & $\begin{array}{c}\text { Membuat ketertarikan anak } \\
\text { bertambah }\end{array}$ \\
\hline 10 & Skor HP, XP, hukuman & Membuat lebih tertarik belajar \\
\hline
\end{tabular}

\section{DAFTAR PUSTAKA}

[1] Salen, K., \& Zimmerman, E. (2004). Rules of Play: Game Design Fundamentals. MIT Press, Cambridge, Ma.

[2] Hagglund, P. (2012). Taking Gamification to the Next Level. UMEA Universitet.

[3] Deterding, S., Dixon, D., Khaled, R., \& Nacke, L. (2011). From Game Design Elements to Gamefulness: Defining "Gamification". MindTrek'11.

[4] Erenli, K. (2012). The Impact of Gamification A Recommendation of Scenarios for Education. IEEE, 1.

[5] Pratama, A. M., Alamsyah, A., \& Peranginangin, Y. (n.d.). Studi Komparasi Pembelajaran Mata Kuliah di Universitas Telkom Menggunakan Octalysis: Complete Gamification Framework dan Penerapan Game Mechanics pada Online Learning. 3-4.

[6] Dijkstra, J. (2013). Machinations Framework - Final Paper. Method Engineering 2012/2013 - Assignment 4, 3.

[7] Nicolescu, A. (2014, April 28). Black box techniques. Retrieved from https://www.qualitance.com/blog/black-box-techniques

[8] Octalysis: Complete Gaming Framework - Yu-kai Chou. (2015, March 1). Retrieved from Yu-kai Chou: Gamification \& Behavioral Design Learn how to use Gamification to make a positive impact on your work and life: http://yukaichou.com/gamification-examples/octalysis-completegamification-framework/ 